\title{
Optimising disruptive approaches: extending academic roles and identities in higher education
}

\author{
Anne Quinney \\ Bournemouth University, UK \\ Carly Lamont \\ Bournemouth University, UK \\ David Biggins \\ Bournemouth University, UK \\ Debbie Holley \\ Bournemouth University, UK
}

\section{Abstract}

Responding to the changing landscape of higher education (HE) requires the development and implementation of flexible and imaginative approaches to continually inspire, engage and support academics and professional services staff in delivering high quality studentcentred learning experiences. At Bournemouth University (BU), the cross-university Centre for Excellence in Learning (CEL) was created to promote, support and co-ordinate pedagogic initiatives and embed the explicit valuing of teaching and learning into all aspects of university life. It represents a collaborative, inter-disciplinary and transdisciplinary model with multiple stakeholder voices. Operationalised through the secondment of academics two days a week, and taking a thematic approach, Theme Leaders 'bid' for the secondment, and drive forward an agreed agenda. The BU 'Fusion' corporate strategy promotes clear links between Pedagogy, Professional Practice and Research, complemented by the current CEL themes of: Employability; Innovation in Technology Enhanced Learning and Innovative Pedagogies; Assessment and Feedback.

We believe that the sustainability and creativity required to deliver this agenda are promoted through the building of strong networks, the sharing of challenges and the collaborative development of solutions, however, as academics moving into the realms of learning development, our roles and identities are constantly being challenged, contested, 
and reframed by the responses of peers, students and our wider disciplinary roots. This paper offers a model for mapping and managing change and optimising these and other 'disruptive' practices within HE institutional settings, and considers the flexible and blended academic identities that facilitate this approach.

Keywords: academic roles; academic identities; education innovation; leading change.

\section{Introduction}

Higher education (HE) has undergone a transformation of the context within which universities operate (BIS, 2015; OFFA, 2015; DCM and BIS, 2016). As predicted by Noble (2002) in his seminal work, Digital Diploma Mills; the reification and commodification of HE led to policies of 'massification'. In the UK, pressure has come from governments requiring more direct inputs into the economy and society, leading to the introduction of professionally qualifying 'newly -academic' programmes, such as social work, nursing, business studies and teaching (Findlow, 2012). The ever-increasing horizontal reach of HE and the notion of lifelong learning (Churchman and King, 2009) has led to an even greater diversification of the student body, driven by a changing population with more varied aspirations. Newer professions and occupational groups seeking recognition and status have strived to become degree bearing bodies (Henkel, 2010). Thus, privatisation, increased means of controlling expenditure, along with more stringent forms of accountability, have been imposed on HE (Lamont and Nordberg, 2014). These changes have put pressure on HE institutions to take greater responsibility for their futures, forcing them to secure additional sources of income and recruit new student populations (Henkel, 2010). This had led universities to reconsider their approaches and priorities in terms of excellence in research and teaching, and at Bournemouth University (BU) these are positioned as part of the tri-part 'Fusion' strategy, encompassing and 'fusing' Research, Education and Professional Practice (see Figure 1). Fusion is a concept at the heart of the university strategy, combining inspirational teaching, internationally-acknowledged research and exemplary professional practice to create a continuous and productive exchange of knowledge. 
This approach has led to the creation of the Centre for Excellence in Learning (CEL), tasked with harnessing pedagogic synergies across the university, inspiring new research and sharing best practice.

\section{Figure 1. The Fusion triangle.}

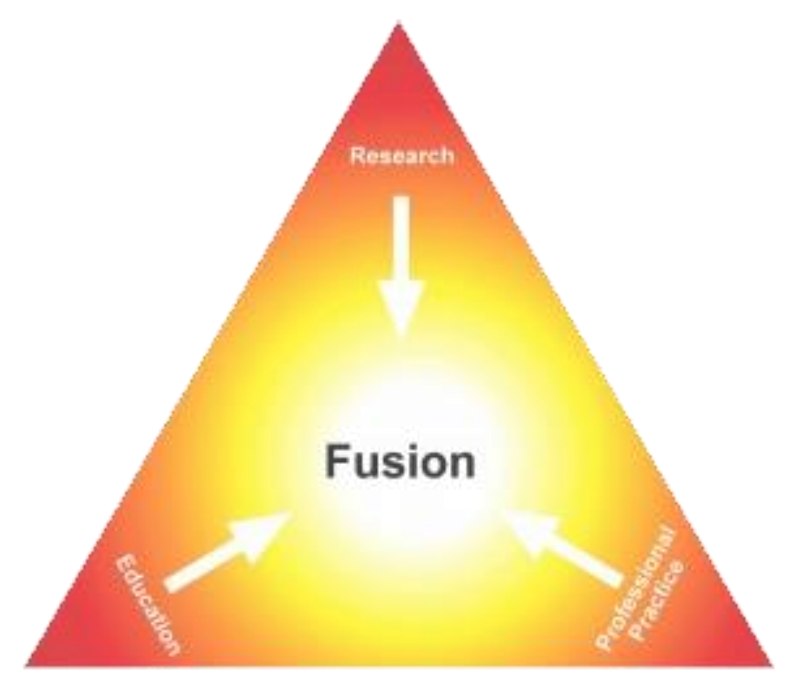

Established three years ago, the mission of CEL is to make a significant contribution to the Fusion strategy by enhancing the student learning experience across the university. It seeks to do this by: developing and supporting collaborative communities to inspire excellence in learning practice across BU and elsewhere; supporting an innovative and creative environment, enabling staff to creatively use new purpose-built learning spaces; building strong mechanisms for sharing good educational practice; and adding value to existing pedagogical practice. Through channeling the energy, knowledge and experience of academic and professional service staff, CEL provides a focal point for leadership, direction and support to improve and innovate education practice. CEL is structured to enable it to focus resources and attention on three key areas of learning and teaching: assessment and feedback; work-based learning and employability; and technology enhanced learning (TEL). The CEL team, working collaboratively, support pedagogic research and evaluation leading to high quality outputs that have significant impact within and beyond the university. Their acknowledged commitment to teaching and learning development is reflected in requests for them to provide consultancy (in the form of interactive workshops) to teams, departments and faculties engaged in educational change and development. 


\section{The CEL Themes}

The assessment and feedback theme promotes best practice and excellence in the assessment of students' work and the provision of timely and developmental feedback to inform future learning, working in partnership with faculties and the Students' Union to review and rewrite institutional policy and develop and disseminate innovative and effective assessment practices. The work-based learning and employability theme recognises the importance of understanding the employment landscape so that successful practices can be developed and shared to inform teaching, and staff can engage in the pedagogy of employment. The technology enhanced learning (TEL) theme seeks to harness available technologies to develop the competencies and confidence of staff, and to engage and enthuse students in their studies. All three themes have associated sponsored projects, research and publications, and working across the themes acknowledges the interconnectedness and symbiosis of teaching and learning in higher education intuitions (HEls). The themes provide focus for teaching and learning activity within the university and enable CEL to deliver the education/pedagogy component of the Fusion triangle. CEL promotes inspirational teaching, internationally-acknowledged research, and developments in academic practice to create a continuous and productive exchange of knowledge to generate and promote innovative ideas in teaching and learning practices, with theme leaders acting as change agents.

Influenced by the ideas of Boyer (1990) on the scholarship of teaching and learning, in which academics reflect on and research their own practice, the CEL approach is: collaborative, entailing working alongside, enthusing and inspiring colleagues and students; interdisciplinary, through the sharing of ideas between disciplines to generate new solutions; and transdisciplinary, in the focusing on pedagogic ideas and principles common to all staff and which transcend disciplinary boundaries. Integral to the approach is the notion of social justice by which transformation is achieved through critical engagement, authentic learning experiences, and reciprocity (Leibowitz and Bozalek, 2015). Examples include the provision of departmental consultations and workshops on assessment and feedback, employing interactive group work practices; the development of a technology enhanced learning toolkit; collaborative working with the Students' Union to tackle seemingly intractable 'wicked' problems (Rittel and Webber, 1973) in relation to assessment and feedback; pedagogic co-creation projects, including employing students as technology trainers to support academics in becoming more adept with new 
technologies to support learning and teaching; knowledge-exchange activities, including staff development for staff delivering 'HE in FE'; input into the Post-Graduate Diploma in Educational Practice programme for academic staff; and a CELebrate week showcasing innovation, new ideas and inspirational guest speakers. The university Peer Assisted Learning (PAL) mentoring scheme ensures that all students begin work placement with an improved understanding of professional workplace behaviours, thereby ensuring the university retains its reputation with placement and graduate employers. We drew upon the experiences of PAL schemes within other HE institutions, particularly those that had successfully scaffolded the use of peer learning to support employability (Keenan, 2014).

\section{Model of change}

The model of educational innovation underpinning our work is adapted from that proposed by Hutchings and Quinney (2015) (Figure 2) which articulates the process of negotiating complexity as a triple helix, with research orientations, education strategies, and technology affordances as the three strands which have the potential to trigger transformation. These three strands share synergies with the BU CEL priorities. Building on earlier work (Hutchings et al., 2010; 2013a; 2013b), Hutchings and Quinney (2015, p.108) recognise and explore the challenges that change agents face when researchinformed educational initiatives are 'experienced as too uncomfortable, too difficult or simply too unwelcome and therefore resisted or rejected', or where academics may be 'uncertain, unconvinced or indifferent' about educational initiatives (Hutchings et al., 2010, p.201) and have proposed strategies for negotiating the complexity of the higher education environment, with the aim of achieving optimum disruption (Hutchings et al., 2010). Whilst this model was developed in the context of a health and social care curriculum, the model is transferable to other disciplines and to university-wide settings, acknowledging that in any context there will be expected and unexpected outcomes to negotiate. Seemingly competing agendas or strategies can be negotiated by employing one or more of the effective processes advocated in the model. 
Triple Helix Model of Change

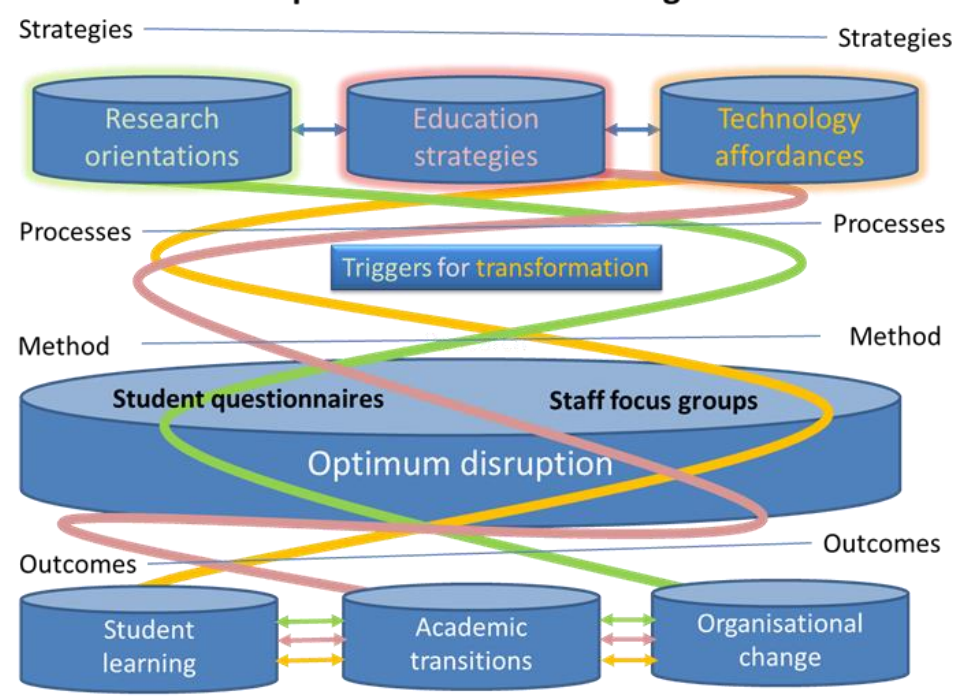

Negotiating Complexity for Transformation

Figure 2. Hutchings and Quinney (2015).

In the work of CEL, research orientations focus on pedagogic research, new education strategies are pioneered, evaluated or disseminated, and the technology affordances are utilised in the technology enhanced learning toolkit developed by one of the theme leaders. Triggers for educational transformation support effective student learning, academic role transitions and the organisational change required to introduce and sustain an excellent teaching and learning environment. These triggers, in the form of CEL theme leader activities, seek to positively disrupt the current culture and develop agility and resilience to provide a student-centred educational experience.

In the context of CEL, the staff and student engagement is supported by a weekly blog, cocreation projects, collaborative working, team and departmental consultations, and masterclasses, rather than the questionnaires and focus groups utilised by Hutchings and Quinney (2015). The literature on academic identities is useful here to help understand the tensions created by introducing new initiatives into an environment that is in constant flux.

As other research suggests (Baruch and Hall, 2004; Navis and Glynn, 2011), changing organisational conditions or cultures creates role conflicts (in this case, for academics) that continue to unsettle or disrupt both individuals and the organisations in which they work. The role of an academic has extended significantly as organisational changes have become established, requiring academics to contribute to institutional research and development, enterprise and community partnership, as well as teaching and learning. 
Involvement in this diverse range of groups and activities often presents an overlap, which has implications for the identities of the staff involved (Gordon and Whitchurch, 2010). Delanty (2008) argues that pressure to perform a variety of roles leads to an individual developing multiple (sometimes conflicting) identities. There lies the potential for incongruence between self-identity (an individual's personal identity), the collective identity of a group, and the demands of the organisation. He adds, universities 'do not easily articulate a collective identity that is capable of acknowledging the numerous identity projects that arise within it' (Delanty, 2008, p.126) often resulting in identity conflicts. For clarification, an identity project, according to Giddens (1991), is one that has no end point, being continuous and reflexive, representing an on-going effort to make sense of who we are (Geijsel and Meijers, 2005). In the case of CEL, the theme leaders are seconded parttime to the role and retain their discipline focus in their respective faculties, with the linkages being represented by their active engagement in pedagogic initiatives and research activities in each of their distinct roles.

The contemporary field of academia is a contested one involving a continuous struggle with the representations its agents have of it (Archer, 2008; Delanty, 2008, Gordon and Whitchurch, 2010). Organisational members may well have opposing views about what it means (or might mean) to be an academic and hold various conflicting interests and identity constructions. While research reputation has undoubtedly become a priority within $\mathrm{HE}$, as articulated in the Research Assessment Framework, the requirement to generate income has also permeated the role of academic staff, encouraging individuals to secure independent commercial ventures. For growing numbers, academic work is internally scrutinised, both administratively and academically, with pay progression and job tenure being performance dependent. Archer (2008, p.386) contends this recent shift in priorities has created 'new forms of relationships, knowledge and academic labour' and the concept of the 'corporate' university which, according to Archer (2008), Henkel (2005; 2010) and Dent and Whitehead (2002), has the potential to disrupt what it means to be an academic and what constitutes academic work. What it means to be an academic is interesting in itself and Williams (2008) invites us to question whether or not academe can be considered a profession and, if so, where the professionalism of academics may lie? He also asks, are academics professionals as discipline experts or as educators? The CEL theme leaders arguably occupy both domains 
Adding to the complexity of understanding the role and identity of academics, Baruch and Hall (2004, p.6) suggest changing conditions often lead to a greater awareness of identity and how 'this may be shaped by individual academic interests or by the interests of the institution'. Clearly, a significant redefinition of the academic profession has taken place, leaving some organisational members struggling with the 'regimes of performativity' (Archer, 2008, p.392) whilst attempting to make sense of who they are and the multiple roles they are to assume. Traditionally academics may have been reluctant to undertake pedagogic rather than subject-based research out of concern for the opportunities for career progression, or to identify with learning and teaching advancements as their primary focus. Nevertheless, with increasing numbers of Doctor of Education or Professional Doctorate routes being offered, these identifies are being reshaped and valued, and the Fusion agenda provides career progression routes which recognise the importance of pedagogic practice and pedagogic research.

Graham (2012) has drawn attention to changing academic identities and roles as the HE sector changes in response to government initiatives and economic realities, creating the potential for discordance between individual practices and organisational policy. However, an optimistic view is that within these spaces and intersections exists the opportunities for creativity and transformation (Smith, 2010) and these ideas are central to the work of CEL. Encapsulated in Barnett's work is Heidegger's (Heidegger 2002, cited Barnett, 2007) belief that the questions of 'being' and of 'value' are brought together in the university. Whilst university 'top down' policies refocus our efforts on the student experience, in the contemporary context of external scrutiny, through league tables and the National Student Survey, Barnett (2007, p.3), in his philosophically orientated text, asks us to consider 'what forms of 'student experience' are likely to prompt a student's continuing engagement with her studies'. This question is informed by an arguably radical perspective which requires the individual student to be the focus, and whilst working in partnership with the Students' Union at BU it is important not to lose sight of individual student experiences and voices, in a consideration of the whole.

Collaborative conversations with colleagues from other institutions tell us that the triggers for change experienced at BU are common in the HE sector and include on a national scale the introduction of the Teaching Excellence Framework, (TEF) alongside the Research Excellence Framework (REF). On an institutional level, the strategic plan which articulates the priorities and future trajectory of the institution has an impact on the ability 
of the wider staff team to feel equipped to deliver these objectives (Biggins et al., 2016). This requires individual and organisational agility and resilience to facilitate the emergence of new staff roles and identities. In doing so, the rapid increase in technology enhanced learning (TEL) must be recognised, and the resultant changing relationships between staff who increasingly occupy a wider range of roles, and between staff and students. In one CEL project, identities and roles are being reversed, as students are acknowledged as occupying a more expert role in technology and are employed to train and support academics in becoming more adept with new technologies to support learning and teaching.

Changing identities and blurring of boundaries, whereby academic identities are continually being revised and new spaces occupied, are being recognised with the notion of a 'blended academic', whose role might span academic and professional domains within a university, with a mixed portfolio of roles and for whom strong lateral networks are important, both within and outside the host university (Whitchurch, 2008). These notions fit well with the CEL Theme Leader roles, with the emphasis on teaching and learning practices and pedagogic research as an alternative career route to the traditional subject research-focused career trajectories.

The optimal disruptions were seen as situationally driven in the study by Hutchings et al. (2010) and across the sector it is common for staff to be working in an environment of continuous disruptive practices. CEL-supported incentives may encourage staff to develop their identities and extend their professional boundaries in the form of Teaching and Learning Fellowships; recognition of their teaching and learning development through accredited Post-Graduate Diploma programmes; Higher Education Academy Fellowship; acknowledgment of pedagogic practice development and research in a career progression framework; and to occupy what Whitchurch (2008) refers to as a third space, where creativity is encouraged in a supportive and stimulating environment.

\section{Conclusion}

Negotiating and merging multiple identities of 'teacher/lecturer', 'researcher' and of learning technologist, whilst raising the profile of and celebrating pedagogic research, is not without challenges. Whilst Barnett (2007) talked about being a student in an age of 
uncertainty, it is equally challenging being an academic in uncertain times and with new frameworks to assess teaching quality as well as research quality. This requires institutional, departmental and team recognition of the centrality of the scholarship of teaching and learning if academic staff are to embrace and juggle effectively these new roles and identities. The work of CEL signals to the wider university a recognition of and commitment to the scholarship of learning and teaching, which requires secure underpinning by individual, cultural and strategic shifts, and acknowledges that pedagogic research and practice is given parity with discipline specific research and practice.

Facilitating student-centred learning approaches within organisational and role transitions is a common challenge in the HE sector and it cannot be assumed that staff or students will embrace change. Returning to the work of Hutchings et al. (2014, p.106), CEL have adopted their strategies for negotiating the complexity of $\mathrm{HEl}$ cultures and practices by developing a 'shared vision, a robust team approach, the need for ongoing horizon scanning and application of soft skills' to deliver 'optimal disruption'. The CEL approach is transferable to other institutions which seek to harness energy and provide leadership that inspires excellence in learning.

\section{References}

Archer, L. (2008) 'Younger academics' constructions of 'authenticity', 'success' and professional identity', Studies in Higher Education, 33(4), pp. 385-403.

Barnett, R. (2007) A will to learn. Being a student in an age of uncertainty. Maidenhead: OUP/SRHE.

Baruch, Y. and Hall, D.T. (2004) 'The academic career: a model for future careers in other sectors?', Journal of Vocational Behavior, 64(2), pp. 241-62.

Biggins, D., Quinney, A., Lamont, C. and Holley, D. (2016) 'Embedding the value of learning by extending professional boundaries', ALDinHE 2016: The Learning Development Conference. Heriot-Watt University, Edinburgh 21-23 March. 
Boyer, E. (1990) Scholarship reconsidered: priorities of the professoriate. Princeton NJ: The Carnegie Foundation for the Advancement of Teaching.

Business Innovation and Skills (2015) Fulfilling our potential: teaching excellence, social mobility and student choice. Available at:

https://www.gov.uk/government/uploads/system/uploads/attachment data/file/4742 27/BIS-15-623-fulfilling-our-potential-teaching-excellence-social-mobility-andstudent-choice.pdf Accessed: 14 October 2017).

Churchman, D. and King, S. (2009) 'Academic practice in transition: hidden stories of academic identities', Teaching in Higher Education, 14(5), pp. 507-516.

Delanty, G. (2008) 'Academic identities and institutional change', in Barnett, R. and DiNapoli, R. (eds.) Changing identities in higher education: voicing perspectives. London: Routledge, pp. 124-33.

Dent, M. and Whitehead, S. (2002) Managing professional identities: knowledge, performativity and the 'new' professional [Kindle edition]. London and New York: Routledge.

Department for Culture, Media and Sport and Department for Business, Innovation \& Skills (2016) Digital skills for the UK economy. Available at:

https://www.gov.uk/government/publications/digital-skills-for-the-uk-economy (Accessed: 19 January 2016).

Findlow, S. (2012) 'Higher education change and professional-academic identity in newly 'academic' disciplines: the case of nurse education', Higher Education, 63(1), pp. 117-133.

Geijsel, F. and Meijers, F. (2005) 'Identity learning: the core process of educational change', Educational Studies, 31(4), pp. 419-430.

Giddens, A. (1991) Modernity and self-identity: self and society in the late modern age. Cambridge: Polity Press. 
Gordon, G. and Whitchurch, C. (2010) Academic and professional identities in higher education: the challenges of a diversifying workforce [Kindle edition]. New York and London: Routledge.

Graham, C. (2012) 'Transforming spaces and identities: the contribution of professional staff in learning spaces in higher education', Journal of Higher Education Policy and Management, 34(4), pp. 437-452.

Henkel, M. (2005) 'Academic identity and autonomy in a changing policy environment,' Higher Education, 49(1-2), pp. 155-176.

Henkel, M. (2010) 'Change and continuity in academic and professional identities', in Gordon, G. and Whitchurch, C. (eds.) Academic and professional identities in higher education: the challenges of a diversifying workforce [Kindle edition]. New York and London: Routledge, pp. 3-12.

Hutchings, M. and Quinney, A. (2015) 'The flipped classroom, disruptive pedagogies, enabling technologies and wicked problems: responding to 'the bomb in the basement", Electronic Journal of e-Learning, 13(2), pp. 106-119.

Hutchings, M., Quinney, A. and Galvin, K. (2014) 'Negotiating the triple helix: harnessing technology for transformation', in Yanez, T., Rodriguez, O. and Griffith, P. (eds.) Proceedings of the 9th International Conference on e-Learning. Technical University Federico Santa María, Valparaiso, Chile 26-27 June.

Hutchings, M., Quinney, A. and Scammell, J. (2010) 'The utility of disruptive technologies in interprofessional education: negotiating the substance and spaces of blended learning', in Bromage, A., Clouder, L., Thistlethwaite, J. and Gordon, F. (eds.) Interprofessional e-learning and collaborative work: practices and technologies. Hershey PA: IGI, pp. 190-203.

Hutchings, M., Scammell, J. and Quinney, A. (2013a) 'Praxis and reflexivity for interprofessional education: towards an inclusive theoretical framework for learning', Journal of Interprofessional Care, 27(5), pp. 358-366. 
Hutchings, M., Quinney, A., Galvin, K. and Clark, V. (2013b) 'The yin/yang of innovative technology enhanced assessment for promoting student learning', in Greener, S. (ed.) Case studies in elearning research for researchers, teachers, and students. Reading: Academic Publishing International, pp. 62-79.

Keenan, C. (2014) Mapping student-led peer learning in the UK. York: Higher Education Academy. Available at: https://www.heacademy.ac.uk/sites/default/files/resources/Peer led learning Keen an Nov 14-final.pdf (Accessed: 16 March 2015).

Lamont, C. and Nordberg, D. (2014) 'Becoming or unbecoming: contested academic identities', British Academy of Management Conference. Belfast 9-11 September.

Leibowitz, B. and Bozalek, V. (2015) The scholarship of teaching and learning from a social justice perspective. Teaching in Higher Education. DOI: 10.1080/13562517.2015.1115971.

Navis, C., and Glynn, M.A. (2011) 'Legitimate distinctiveness and the entrepreneurial identity: influence on investor judgements of new venture plausibility', Academy of Management Review, 36(3), pp. 479-499.

Noble, D.F. (2002) 'Technology and the commodification of higher education', Monthly Review, 53(10) [Online]. Available at:

https://monthlyreview.org/2002/03/01/technology-and-the-commodification-ofhigher-education/ (Accessed: 14 October 2017).

Office for Fair Access (OFFA) (2015) Promoting fair access to higher education. Available at: https://www.offa.org.uk/ (Accessed: 14 October 2017).

Rittel, H.W.J. and Webber, M.M. (1973) 'Dilemmas in a general theory of planning', Policy Sciences, 4(2), pp. 155-169.

Smith, J. (2010) 'Academic identities for the twenty first century', Teaching in Higher Education, 15(6), pp. 721-727. 
Whitchurch, C. (2008) 'Shifting identities and blurring boundaries: the emergence of Third Space professionals in UK higher education', Higher Education Quarterly, 62(4), pp. 377-396.

Williams, K. (2008) 'Troubling the concept of the 'academic profession' in the $21^{\text {st }}$ Century in higher education', Higher Education, 56(5), pp. 533-544.

\section{Author details}

Anne Quinney is the Theme Leader for Innovative Pedagogies, Assessment and Feedback in the Centre for Excellence in Learning at Bournemouth University.

Carly Lamont is a Lecturer in the Faculty of Management and previously the Theme Leader for Employability and Work-based Learning in the Centre for Excellence in Learning at Bournemouth University.

David Biggins is an Academic Learning Designer in the Centre for Excellence in Learning at Bournemouth University.

Debbie Holley is Professor of Learning Innovation and Head of the Centre for Excellence in Learning at Bournemouth University. 